\title{
ANÁLISE DAS PATOLOGIAS EM PAVIMENTOS FLEXÍVEIS
}

\author{
SANTOS, ANA LUIZA F. \\ Engenheira Civil \\ UNIVASF \\ Bahia; Brasil \\ analuiza.fonseca.s@gmail.com
}

\author{
GRANJA, JAILMA M. M. \\ Graduanda em Engenharia Civil \\ UNIVASF \\ Bahia; Brasil \\ jailma_granja_@hotmail.com
}

\author{
BARBOSA, ANDERSON H. \\ Professor \\ UNIVASF \\ Bahia; Brasil \\ anderhb80@gmail.com
}

\section{RESUMO}

O modal rodoviário é o mais utilizado no Brasil, destacando a sua importância no transporte de pessoas e mercadorias. As condições de conforto, segurança, e seu estado de conservação são fundamentais para a eficiência desta modalidade. O planejamento, projeto, execução e a manutenção das vias são essenciais para que o pavimento tenha sua vida útil garantida de forma satisfatória. Esse trabalho tem por finalidade analisar as condições de superfície do pavimento flexível de três avenidas, com aproximadamente dois anos de uso, localizado no município de Petrolina - PE. A avaliação se deu em pavimentos flexíveis, e um dos critérios funcionais, o nível de serventia. Com a avaliação dos defeitos, realizado através de registros fotográficos, foi possível verificar o surgimento precoce de algumas manifestações patológicas, assim como identificar as principais causas para o aparecimento desses defeitos e sugerir técnicas de recuperação. Na avaliação do nível de serventia foram realizadas avaliações que classificaram os pavimentos em péssimo a ótimo, no que diz respeito as condições de rolamento e suavidade do pavimento.

Palavras-chave: Pavimento. Pavimento flexível. Manifestações patológicas. Nível de serventia.

\section{ABSTRACT}

The road mode is the most used in Brazil, highlighting its importance in the transport of people and goods. The conditions of comfort, safety, and its state of conservation are fundamental for the efficiency of this modality. The planning, design, execution and maintenance of the roads are essential for the pavement to be satisfactorily guaranteed. The purpose of this work is to analyze the surface conditions of the three-avenue flexible pavement, with approximately two years of life, located in the city of Petrolina - PE. The evaluation took place on flexible pavements, and one of the functional criteria, the level of service. With the evaluation of defects, performed through photographic records, it was possible to verify the early appearance of some pathologies, as well as identify the main causes for the appearance and suggest recovery techniques. In the evaluation of the level of service, was evaluated with very poor to excellent, regarding the rolling conditions.

Keywords: Pavement. Flexible pavement. Pathological manifestations. Level of service. 


\section{INTRODUÇÃO}

O modal rodoviário ainda é a principal modalidade de transporte no brasil. Este apresenta algumas vantagens atrativas por ser fundamental para que a multimodalidade aconteça, por transportar qualquer tipo de carga, pela capacidade de trafegar por qualquer via, ter flexibilidade de rotas e horários, entre outras. Para que esse tipo de modal funcione com qualidade, é necessário ter rodovias bem pavimentadas, em um bom estado de conservação, por isso, é muito importante conhecer a situação atual da infraestrutura rodoviária brasileira.

De acordo com a pesquisa realizada pela confederação nacional de transportes (CNT), em 2016, constatou que dos $103.259 \mathrm{~km}$ pavimentados, 48,3\% dos trechos avaliados receberam classificação regular, ruim e péssimo. Os problemas relacionados ao pavimento geram um aumento médio de $24,9 \%$ no custo operacional do transporte. Diante desse cenário, é notória a necessidade de um projeto de pavimentação bem elaborado, com execução correta e uma manutenção constante para garantir a vida útil do pavimento.

O presente trabalho visa reunir as informações necessárias para avaliar as condições dos pavimentos, identificar os tipos de patologias e aplicar as correções mais indicadas, que devem ser tomadas de acordo com as severidades, auxiliando de forma mais prática na solução para os problemas apresentados, além de analisar subjetivamente o grau de conforto e suavidade ao rolamento do pavimento, através do Valor de Serventia Atual (VSA).

\section{PAVIMENTOS FLEXÍVEIS}

É aquele em que todas as camadas sofrem deformações elásticas significativas sob o carregamento aplicado e, portanto, a carga se distribui em parcelas aproximadamente equivalentes entre as camadas (DNIT, 2006, p.99). Camadas essas que não trabalham a tração.

De acordo com Balbo (2007), a carga atuante nesse tipo de pavimento impõe na estrutura um campo de tensões concentrado, próximo ao ponto de aplicação da carga, o que proporciona maiores magnitudes de esforços verticais (pressões) sobre o subleito, quando comparado aos pavimentos rígidos.

Bernucci (2008) declara que, os pavimentos flexíveis são constituídos pela associação de agregados e ligantes asfálticos. É formado por quatro camadas: revestimento asfáltico, base, sub-base e reforço do subleito. O revestimento asfáltico pode ser composto pela camada de rolamento e uma camada de ligação, por vezes denominada de Binder.

A principal vantagem é a rapidez de execução, quanto à construção do pavimento ou as reparações, são mais fáceis e rápidas, podendo assim, liberar o tráfego mais rápido (BROCHADO, 2014, p.16).

Conforme Balbo (2007), os pavimentos flexíveis ou asfálticos são geralmente divididos em duas ou mais subcamadas por razões técnicas, construtivas e de custo. Essa subdivisão se dá pelo emprego de diferentes materiais.

\subsection{Manifestações patológicas dos pavimentos flexíveis}

Os pavimentos são construídos para um determinado tempo de vida útil, iniciando em condições ótimas até o aparecimento de patologias, que antecedem a sua degradação. De acordo com Balbo (2007), o decréscimo da condição ou serventia de um pavimento ao longo do tempo é conhecido como deterioração, dano ou degradação. A velocidade com que a deterioração acorre vai depender de diversos fatores como, as condições ambientais, a qualidade do material utilizado e seu processo construtivo, a capacidade de suporte da estrutura e do subleito, ao volume de tráfego, as cargas que irão atuar no pavimento e ainda, ao comportamento mecânico que é particular a cada estrutura.

É importante frisar que as patologias catalogadas pela Norma DNIT - TER 005/2003, Defeitos nos Pavimentos Flexíveis e Semirrígidos - Terminologia, são utilizadas para cálculo de indicador de qualidade da superfície do pavimento (IGG - Índice de Gravidade Global) e ela será a diretriz principal para as definições de cada patologia, sendo elas:

\subsubsection{Fendas, fissuras e trincas}


Qualquer descontinuidade na superfície do pavimento, que conduza a aberturas de menor ou maior porte, apresentandose sob diversas formas. (DNIT, 2003, p.02). Segundo Bernucci (2008), as fendas são o tipo de defeito mais significativo dos pavimentos asfálticos e são subdivididos de acordo com sua gravidade e tipologia, que são as trincas e fissuras.

A principal causa para o surgimento desse tipo de defeito é o esgotamento dos materiais utilizados nas camadas, devido à tração por flexão dessas camadas, causada pela repetição da passagem de carga dos veículos, Pinto e Preussler (2001) ainda cita outros problemas como as camadas granulares não possuírem camada de suporte, a camada de a superfície possuir uma rigidez elevada ou a má qualidade dos materiais utilizados.

Fissuras são fendas de largura capilar existente no revestimento, posicionada longitudinal, transversal ou obliquamente ao eixo da via, somente perceptível à vista desarmada de uma distância inferior a 1,50 m (DNIT, 2003, p.02). Afirma-se ainda que esse tipo de defeito não causa problemas funcionais ao revestimento, não sendo considerada quanto à gravidade.

As trincas são fendas existentes no revestimento, facilmente visível a olho nu, com abertura superior à da fissura, podendo apresentar-se sob a forma de trinca isolada ou trinca interligada. (DNIT, 2003, p.02).

As trincas isoladas podem ser classificadas como transversal, longitudinal e de retração. Já as interligadas podem se manifestar como "couro de jacaré" e como bloco.

\subsubsection{Afundamento}

Deformação permanente caracterizada por depressão da superfície do pavimento, acompanhada, ou não, de solevamento, podendo apresentar-se sob a forma de afundamento plástico ou de consolidação (DNIT, 2003, p.02). Em geral, tem como prováveis causas a falha na dosagem da mistura asfáltica e falha na seleção de tipo de revestimento asfálticos para a carga solicitante.

Pode ser decorrente de fluência plástica de uma ou mais camadas do pavimento ou do subleito, acompanhado de solevamento, chamada de afundamento plástico. Afundamento de consolidação problema causado pela consolidação diferencial de uma ou mais camadas do pavimento ou subleito sem estar acompanhado de solevamento.

\subsubsection{Ondulação ou corrugação}

Deformação caracterizada por ondulações ou corrugações transversais na superfície do pavimento (DNIT, 2003, p.03), como na Figura 14. As duas se diferenciam apenas pelo comprimento de onda, ou seja, a distância entre duas cristas consecutivas, que no caso da corrugação se apresenta com o comprimento de onda menor que a ondulação.

São popularmente conhecidas como "costelas de vaca" e tem com causa a má execução, instabilidade com relação à mistura, excesso de asfalto ou finos e de água nas camadas subjacentes, contaminação da mistura asfáltica e retenção de água na mesma. Ocorrem com maior frequência em rampas, curvas, subidas, em áreas submetidas à aceleração e frenagem porque estão associadas às tensões de cisalhamento horizontais geradas pelos veículos.

\subsubsection{Escorregamento}

Deslocamento do revestimento em relação à camada subjacente do pavimento, com aparecimento de fendas em forma de meia-lua (DNIT, 2003, p.03). Ocorre principalmente em áreas de frenagem e interseções, quando acontece a baixa resistência da massa asfáltica ou a falta de aderência entre a camada de revestimento e a camada de subjacente.

Balbo (1997) descreve como sendo um deslocamento transversal na mistura asfáltica e tem origem com relação à imprimação inadequada do revestimento sobre a camada subjacente, inadequada compressão da mistura asfáltica antes da liberação da via pra o trafego, a viscosidade inadequada do cimento asfáltico para condições de uso e excesso de ligantes na mistura.

\subsubsection{Exsudação}

Excesso de ligante betuminoso na superfície do pavimento, causado pela migração do ligante através do revestimento (DNIT, 2003, p.03). Apresentam-se em forma de mancha de variadas extensões, com uma espécie de brilho e superfície 
com baixa resistência à derrapagem. Isso se dá por conta da dilatação do asfalto no calor que encontra dificuldade de ocupar espaço devido ao baixo volume de vazios e ao excesso de ligantes, diminuindo também a viscosidade do asfáltico e consequentemente o envolvimento dos agregados grossos.

\subsubsection{Desgaste}

Efeito do arrancamento progressivo do agregado do pavimento, caracterizado por aspereza superficial do revestimento e provocado por esforços tangenciais causados pelo tráfego (DNIT, 2003, p.03).

\subsubsection{Panela ou buraco}

Cavidade que se forma no revestimento por diversas causas (inclusive por falta de aderência entre camadas superpostas, causando o desplacamento das camadas), podendo alcançar as camadas inferiores do pavimento, provocando a desagregação dessas camadas (DNIT, 2003, p.03). É uma manifestação que surge com a evolução de outras, que vai se agravando até chegar ao estágio final de degradação do pavimento. A presença de água é um dos fatores mais importante para o agravamento dessas manifestações patológicas, somando com a falta de tratamento e reparo adequados chega-se a esse estágio de degradação.

\subsection{Valor de Serventia Atual (VSA)}

Capacidade de um trecho específico de pavimento de proporcionar, na opinião do usuário, rolamento suave e confortável em determinado momento, para quaisquer condições de tráfego (DNIT 009/2003).

A Norma DNIT 009/2003 - PRO, afirma ainda que é uma medida subjetiva das condições de superfície do pavimento, feita por um grupo de avaliadores que percorrem o determinado trecho de analise, registrando suas opiniões, que variam de péssimo a ótimo, sobre a capacidade do pavimento de atender as exigências de conforto e suavidade.

A avaliação é calculada pela média de notas, compreendidas em uma escala de 0 a 5 , como mostra a Figura 20 , atribuídas por membros de um grupo de cinco avaliadores que percorrem o trecho em uma velocidade próxima e abaixo da velocidade máxima permitida. O valor de VSA é calculado por: VSA $=\Sigma \mathrm{x} / \mathrm{n}$, onde $\mathrm{x}=\mathrm{VSA}$ individuais admitidos por cada membro avaliador do grupo e $\mathrm{n}=$ número de membros do grupo de avaliadores

\section{METODOLOGIA}

O estudo foi realizado na cidade de Petrolina/PE, em vias locais para a identificação das manisfestações patológicas, bem como da relação do VSA.

Foram realizadas duas análises relacionadas às condições de superfície, uma relacionada às patologias encontradas e outra ao nível de serventia através do Valor de Serventia Atual (VSA), utilizando as seguintes normas do Departamento Nacional de Infraestrutura e Transporte (DNIT):

- $\quad$ DNIT 005/2003 - TER - Defeitos nos pavimentos flexíveis - Terminologia;

- $\quad$ DNIT 009/2003 - PRO - Levantamento para avaliação subjetiva da superfície do pavimento - Procedimento.

As vias escolhidas foram pavimentadas com CBUQ (Concreto Betuminoso Usinado a Quente), tendo aproximadamente dois anos de utilização. Ambas são corredores de ônibus e possuem comprimentos e tráfego distintos.

Foi possível diagnosticar quais foram os defeitos encontrados e através desses dados saber quais as principais patologias e a incidência em pavimentos recém-construídos e/ou recapeados

\section{RESULTADOS E DISCUSSÕES}

Para o VSA de três vias estudadas, os valores são apresentados na Tabela 1. 
Tabela 1 - Avaliação do VSA.

\begin{tabular}{c|c|c|c|c|c|c|c|c}
\hline \multirow{2}{*}{ Avaliador } & \multicolumn{2}{|c|}{ Via 1 (Construido) } & \multicolumn{2}{c|}{ Via 2 (Construído) } & \multicolumn{2}{c|}{ Via 3 (Recapeado) } & \multicolumn{2}{c}{ Via 3 (Construído) } \\
\cline { 2 - 10 } & Avaliação & Padrão & Avaliação & Padrão & Avaliação & Padrão & Avaliação & Padrão \\
\hline 1 & 4,5 & Ótimo & 3,8 & Bom & 0,5 & Péssimo & 4,15 & Ótimo \\
\hline 2 & 4,5 & Ótimo & 3,5 & Bom & 1,5 & Ruim & 4,4 & Ótimo \\
\hline 3 & 4,0 & Ótimo & 3,85 & Bom & 1,5 & Ruim & 4,5 & Ótimo \\
\hline 4 & 4,7 & Ótimo & 3,0 & Bom & 1,5 & Ruim & 3,5 & Bom \\
\hline 5 & 4,5 & Ótimo & 3,0 & Bom & 0,9 & Péssimo & 4,5 & Ótimo \\
\hline Avaliação & $\mathbf{4 , 4 4}$ & Ótimo & $\mathbf{3 , 4 3}$ & Bom & $\mathbf{1 , 1 8}$ & Ruim & $\mathbf{4 , 2 1}$ & Ótimo \\
\hline
\end{tabular}

Nota-se que na via 1, onde o fluxo de veículos é o menor dos três casos, o trecho foi considerado com padrão de conforto ótimo. No caso da via 2, com um fluxo de veículos um pouco mais intenso, esta recebeu uma avaliação de padrão bom. Já para a via 3, o trecho recapeado, que possui alto fluxo de veículos, recebeu avaliação ruim e o trecho que foi construído, foi avaliado como ótimo, em relação ao nível de serventia do pavimento.

Assim, podemos perceber que as avaliações para os trechos de pavimento flexível construído foram consideradas de bom à ótimo, já para o trecho recapeado, o padrão de conforto foi considerado ruim, o que indica uma ineficiência na técnica recuperação desse pavimento.

Em relação às patologias, principalmente nestas 3 vias, foram observdas uma série de problemas, adiante destacados.

Pontos de afundamento, desgaste e buracos foram detectados na via 1, conforme pode ser observado na Figura 1.

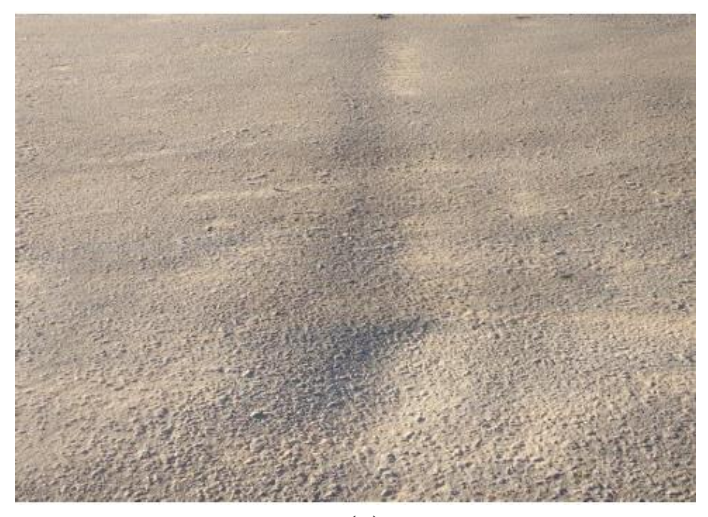

(a)

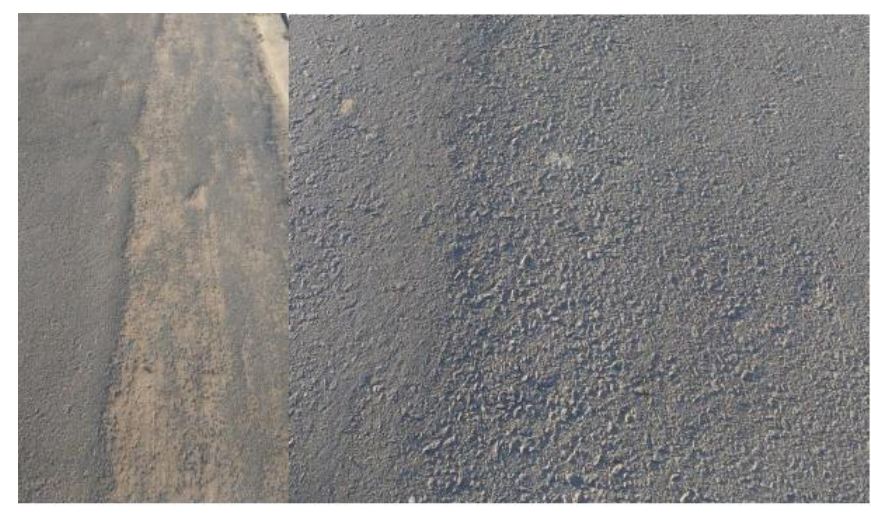

(b)

(c)

Figura 1: Manifestações patológicas detectadas na via 1: (a) afundamento; (b) desgaste; e (c) buracos/panelas.

De forma semelhante, na via 2 também foram detectadas as mesmas patologias da via 1, como pode ser observado na Figura 2. 

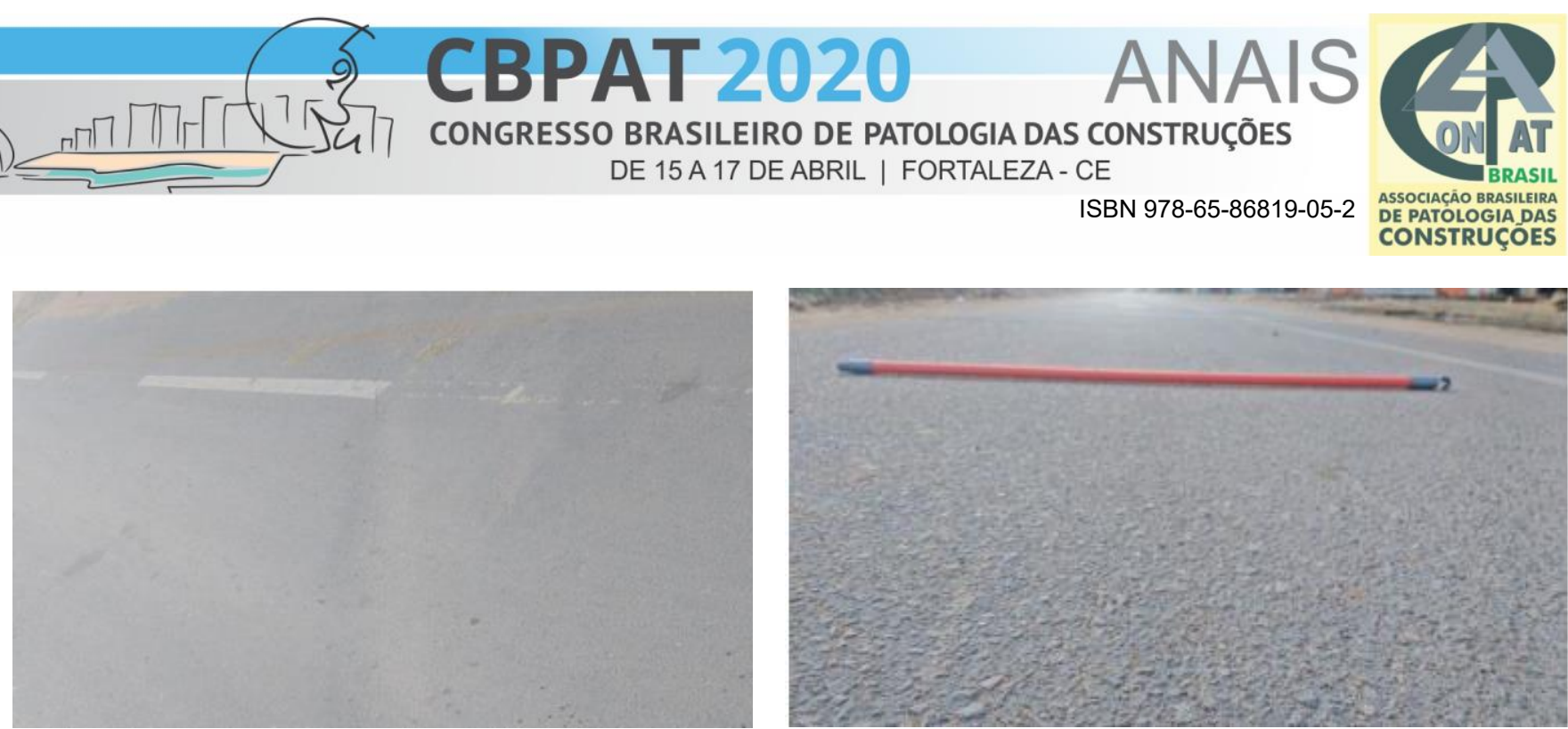

(a)

(b)

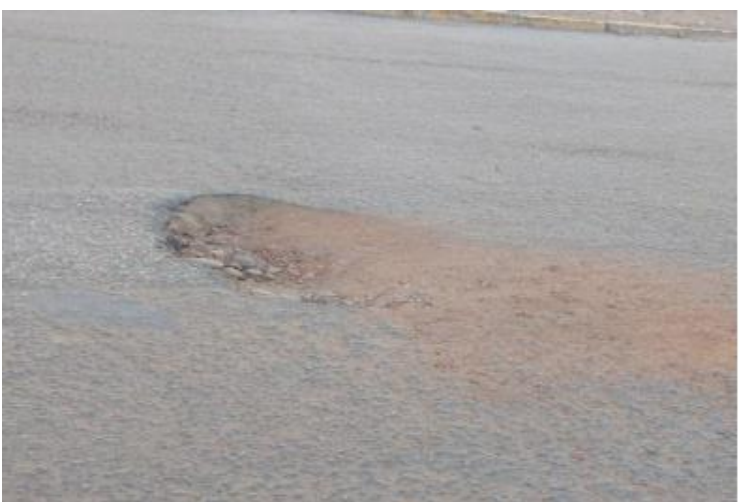

(c)

Figura 2: Manifestações patológicas detectadas na via 2: (a) afundamento; (b) desgaste; e (c) buracos/panelas.

Na via 3, que foi recapeada, só é possivel observar buracos/panelas, como mostrado na Figura 3. Também são observados diversos pontos com remendo (Figura 4).

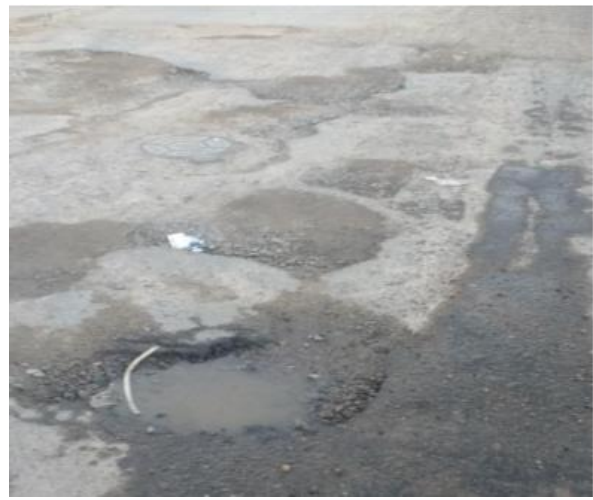

Figura 3: Buracos/panelas encontrados no trecho recapeado da via 3.

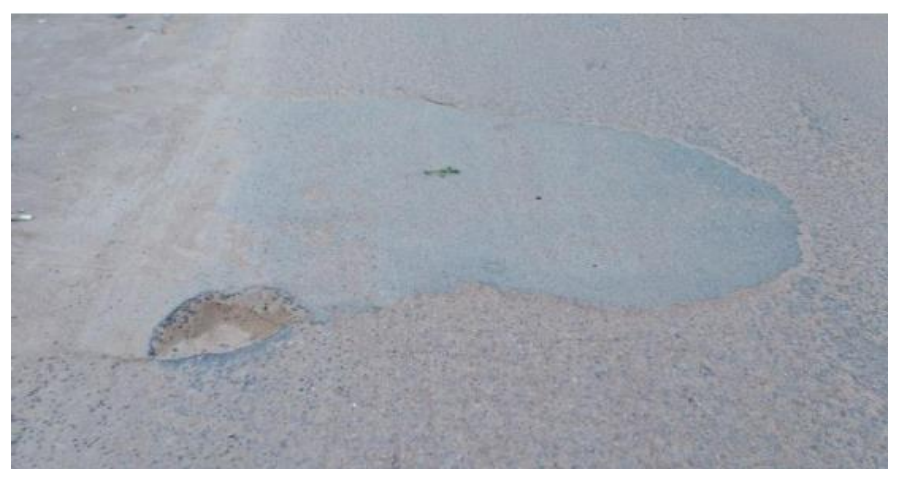

Figura 4: Ponto com remendo na via 3. 
As principais causas estão associadas à deficiência na ligação entre os componentes da mistura betuminosa, principalmente na adesividade entre ligante e adregado, ou sua má formulação.

Esse tipo de defeito é causado por deformações permanentes, seja do revestimento ou nas camadas subjacentes, principalmente pela ação dos pneus que passam no pavimento repetidas vezes. Para a recuperação do pavimento são sugeridas duas técnicas: o recapeamento, que é a construção de mais camadas sobre o pavimento já existente, sendo uma camada para nivelamento e outra de espessura uniforme e a fresagem, que é o corte do revestimento para nivelar e melhorar a qualidade ao rolamento do pavimento, tendo a vantagem de o material retirado poder ser reutilizado.

Esse tipo de patologia surge com a evolução das outras. No caso das vias 1 e 2, ao que parece o surgimento dos buracos foram em trechos com o grau de desgaste um pouco mais avançado, somado aos afundamentos locais. Já no caso da avenida 3, esse defeito aparece por cima do pavimento já recapeado, o que mostra que o recapeamento não foi feito da forma correta. A recuperação pode ser feita atrás de remendos, com tanto que sejam bem executados, com corte, imprimação para selar trincas e em seguida aplicação do novo pavimento flexível.

Analisando as três avenidas, notou-se que o defeito mais encontrado ao longo de todos os trechos analisados foi o desgaste, seguido do afundamento e o menos observado foi à fenda.

O remendo é uma das técnicas de recuperação mais utilizada no país. Ela se torna uma manifestação patológica quando executada de forma incorreta, gerando problemas no próprio remendo, sendo necessária uma nova recuperação com o tempo. A melhor forma de resolver esse tipo de defeito é arrancar o remendo feito incorretamente e executar um novo de forma correta.

\section{CONCLUSÃO}

Após avaliação e análise das manifestações patológicas encontradas, é notório que os trechos que tiveram o pavimento construído estão em um bom estado de serventia e conforto, porém foram observados defeitos que não deveriam existir por terem, aproximadamente, dois anos de vida útil. Esses defeitos de forma precoce podem estar associados a dois principais fatores: problemas na ligação dos componentes da mistura asfáltica, pelo alto índice de problemas com desgaste do pavimento e possivelmente, por erros relacionados ao estudo de tráfego de veículos que utilizam essas avenidas, visto que todas elas apresentam o afundamento como um dos principais defeitos.

Já para o trecho que foi recapeado através de remendos, é possível observar um conceito ruim no que diz respeito ao padrão de conforto do rolamento. A técnica de recuperação utilizada foi feita de forma incorreta, o que explica a quantidade de buracos existentes nesse trecho. Por isso, o pavimento está no fim da vida útil e é necessária uma reconstrução desse pavimento utilizando a técnica de forma correta.

Assim, foi possível verificar que as vias pavimentadas há aproximadamente dois anos, no município de Petrolina - PE, apesar de estarem em um bom estado de conservação e conforto, apresentam dois tipos de defeitos em todos os trechos de estudo e em alto índice de ocorrência, sendo eles o desgaste e o afundamento. E ainda foi possível constatar, através do VSA, que houve problemas na execução da técnica de reconstrução de pavimentos utilizando os remendos, por conta da precoce e alta degradação do trecho de estudo recapeado.

\section{REFERÊNCIAS}

BALBO, José. T. Pavimentação asfáltica - materiais, projeto e restauração. São Paulo: Plêiade, 2007.

BERNUCCI, L. L. B, et al. Pavimentação asfáltica: Formação básica para engenheiros. $1^{\circ}$ ed. Rio de Janeiro: Petrobrás, ADEBA, 2008.

BROCHADO, Matheus. M. L. Estudo da viabilidade do asfalto pré-misturado a frio em rodovias de médio a baixo tráfego. 2014. 59. Engenharia Civil - Faculdade de Tecnologia e Ciências Sociais Aplicadas (UniCEUB), Brasília.

CNT. Brasil tem apenas $\mathbf{1 2 , 3 \%}$ da malha rodoviária com pavimento. Disponível em: http://www.cnt.org.br/Imprensa/noticia/brasil-tem-apenas-12-da-malha-rodoviariacom-pavimento. Acesso em: 06 de out. 2017. 


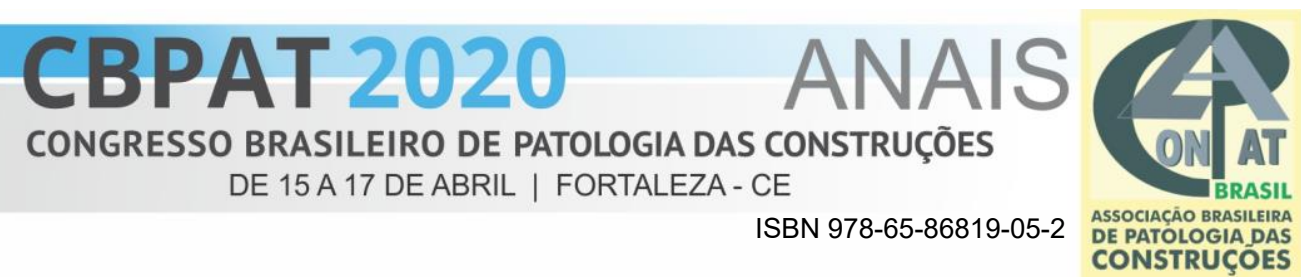

DEPARTAMENTO NACIONAL DE INFRAESTRUTURA E TRANSPORTE - DNIT. Norma DNIT 005/2003 TER - Defeitos nos pavimentos flexíveis e semirrígidos - Terminologia. Rio de Janeiro, 2003.

NORMA DNIT 009/2003 - PRO - Avaliação subjetiva da superfície de pavimentos flexíveis e semirrígidos Procedimento. Rio de Janeiro, 2003.

Manual de pavimentação. Rio de Janeiro, 2006.

PINTO, S.; PREUSSLER, E. Pavimentação rodoviária - conceitos fundamentais sobre pavimentos flexíveis. Rio de Janeiro, 2001. 